\title{
Design of Experiments (DoE) applied to Pharmaceutical and Analytical Quality by Design (QbD)
}

\author{
Isa Martins Fukuda1, Camila Francini Fidelis Pinto ${ }^{1}$, Camila dos Santos Moreira ${ }^{1}$, \\ Alessandro Morais Saviano', Felipe Rebello Lourenço ${ }^{1, *}$
}

${ }^{1}$ Department of Pharmacy, Faculty of Pharmaceutical Sciences, University of São Paulo, São Paulo, Brazil

\begin{abstract}
According to Quality by Design (QbD) concept, quality should be built into product/method during pharmaceutical/analytical development. Usually, there are many input factors that may affect quality of product and methods. Recently, Design of Experiments (DoE) have been widely used to understand the effects of multidimensional and interactions of input factors on the output responses of pharmaceutical products and analytical methods. This paper provides theoretical and practical considerations for implementation of Design of Experiments (DoE) in pharmaceutical and/or analytical Quality by Design $(\mathrm{QbD})$. This review illustrates the principles and applications of the most common screening designs, such as two-level full factorial, fractionate factorial, and Plackett-Burman designs; and optimization designs, such as three-level full factorial, central composite designs (CCD), and Box-Behnken designs. In addition, the main aspects related to multiple regression model adjustment were discussed, including the analysis of variance (ANOVA), regression significance, residuals analysis, determination coefficients $\left(\mathrm{R}^{2}, \mathrm{R}^{2}\right.$-adj, and $\mathrm{R}^{2}$-pred), and lack-of-fit of regression model. Therefore, DoE was presented in detail since it is the main component of pharmaceutical and analytical QbD.
\end{abstract}

Keywords: Design of Experiments (DoE). Quality by Design (QbD). Factorial Designs. Central Composite Designs (CCD). Box-Behnken Designs. Response Surface Methodology (RSM).

\section{INTRODUCTION}

Since the introduction of Quality-by-Design $(\mathrm{QbD})$ concepts, it has been accepted that quality of pharmaceutical products should be designed and built during the manufacturing process. According to Juran (Yu et al., 2014), most of quality problems are related to the way in which a pharmaceutical product was designed. A poor-designed pharmaceutical product will show poor safety and efficacy, no matter how many tests or analyses have been done to verified its quality. Thus, $\mathrm{QbD}$ begins with the recognition that quality will not be improved by merely increasing analyses of pharmaceutical products. In other words, quality must be built into the product. (Yu et al., 2014).

$\mathrm{QbD}$ is "a systematic approach to pharmaceutical development that begins with predefined objectives and emphasizes product and process understanding and

*Correspondence: F. R. Lourenço. Departamento de Farmácia, Faculdade de Ciências Farmacêuticas, Universidade de São Paulo. E-mail: feliperl@usp.br process control, based on sound science and quality risk management" (Yu et al., 2014). Application of QbD will provide knowledge and scientific understanding to support pharmaceutical development (Sangshetti et al., 2017). Pharmaceutical QbD goals may include: a) to achieve meaningful product quality specifications; b) to increase process capability and reduce product variability; c) to increase pharmaceutical development and manufacturing efficiencies; and d) to enhance cause-effect analysis and regulatory flexibility (Yu et al., 2014).

The adoption of risk-based approaches and pharmaceutical QbD have been encouraged by most of regulatory agencies worldwide (Yu et al., 2014; Bhutani et al., 2014). Pharmaceutical QbD concepts has been used to enhance manufacturing pharmaceutical products in terms of "Six-sigma" approach. "Six-sigma" is a system of practices to achieve process improvement, which leads to a significantly reduced chance of out-of-specification (OOS) products. The significant number of OOS results reported indicates that this is an issue to pharmaceutical industries (Peraman, Bhadraya, Reddy, 2015). 
However, many times the problems in achieving the required "six-sigma" performance is not due to manufacturing issues, but due to poor analytical methods robustness and reliability. Several authors described the application of the QbD concepts in the development of analytical methods (Peraman, Bhadraya, Reddy, 2015; Bhutani et al., 2014). Analytical QbD is useful in the development and optimization of robust and cost-effective analytical methods. Implementation of analytical QbD provides a better solution to OOS results, as well as it also reduces the risk of method failure.

Traditionally, the development and optimization of pharmaceutical products and analytical methods have been carried-out by analyzing one factor at time (OFAT approach) (Bezerra et al., 2008; Candioti et al., 2014; Politis et al., 2017). One of the factors is changed within an appropriate range (or levels), while the others are kept constants. In addition to demanding a high number of experiments, the OFAT approach does not allow to evaluate the existence of interaction between the factors, which may lead to an inadequate conduction of the development and optimization (Bezerra et al., 2008; Candioti et al., 2014; Politis et al., 2017). To overcome these limitations, design of experiments (DoE) may provide better results with few number of experiments. DoE is a set of statistical tools which include screening designs; and optimization designs (Bezerra et al., 2008; Candioti et al., 2014; Politis et al., 2017).

DoE is the main component of pharmaceutical and analytical QbD. Thus, the present paper provides theoretical and practical considerations for implementation of Design of Experiments (DoE) in pharmaceutical and/or analytical Quality by Design (QbD).

\section{STEPS OF PHARMACEUTICAL QUALITY BY DESIGN AND ANALYTICAL QUALITY BY DESIGN}

QbD comprises all elements of pharmaceutical development, which will allow to design a quality product and its manufacturing process to consistently deliver the intended performance concerning its safety and efficacy. Using QbD approach, pharmaceutical development will provide a complete understanding of the product and its manufacturing process (Sangshetti et al., 2017; Zhao, Mao, 2017; Yu et al., 2014).

Analytical methods are considered an integral part of pharmaceutical development (Bhutani et al., 2014). Thus, the application of $\mathrm{QbD}$ approach to analytical method development is justifiable and a recommended strategy to attain regulatory flexibility, to reduce out-of-specification results, to achieve a high degree of robustness and a costeffective analytical method (Peraman, Bhadraya, Reddy, 2015; Bhutani et al., 2014).

\section{Establishing of Quality Target Product Profile (QTPP) / Analytical Target Profile (ATP)}

Quality Target Product Profile (QTPP) is a summary of quality characteristics of pharmaceutical product that must be achieved to guarantee safety and efficacy. In other words, QTPP consists in the definition of expectations in final pharmaceutical product (Sangshetti et al., 2017; Yu et al., 2014). Considerations for QTPP should include the intended use in clinical setting, route of administration, dosage form, delivery system, dosage strength, container closure system, factors affecting pharmacokinetics properties, and product quality criteria (such sterility, purity, stability, among others) (Sangshetti et al., 2017; Zhao, Mao, 2017; Yu et al., 2014).

Analytical Quality by Design (AQbD) starts with the definition of Analytical Target Profile (ATP). ATP defines the goal of the analytical method, which will drive the method selection, design, and development activities (Peraman, Bhadraya, Reddy, 2015; Bhutani et al., 2014). In other words, ATP is a statement of what should be measure (for example, active pharmaceutical ingredient - API), in what it should be measured (for example, in pharmaceutical dosage form), and why/when it should be measured (for example, during stability study). A required level of confidence (target measurement uncertainty usually estimated from accuracy and precision) should be state into ATP definition, in order to ensure the quality of analytical results (Bhutani et al., 2014).

It seems to be obvious that the main goals of a new product or method should be defined before its development. However, over the years, this approach has been seldom adopted. A well-defined QTPP (or ATP) avoid time- and resource-wasting. (Yu et al., 2014)

\section{Identifying of Critical Quality Attributes (CQA) / Analytical Method Performance Characteristics (AMPC)}

Identification of Critical Quality Attributes (CQA) is the next step in pharmaceutical QbD. CQA is chemical, physical, biological or microbiological properties or characteristics of pharmaceutical product (in-process or finished) that must be within appropriated specifications to ensure quality. CQA may include identity, assay, content, uniformity, degradation, products, residual solvents, drug release or dissolution, moisture content, microbial limits, 
and physical properties such as color, shape, size, and friability (Sangshetti et al., 2017; Zhang, Mao, 2017). Potential CQA derived from QTPP are used to guide product and process development. Thus, Critical Material Attributes (CMA) and Critical Process Parameters (CPP) may also be identified in order to achieved CQA and QTPP, consequently (Yu et al., 2014).

Critical Material Attributes (CMA) consists of physical, chemical, biological or microbiological properties that input material must comply to ensure the desired CQA. On the other hand, Critical Process Parameters (CPP) are process parameters such as mixing time, stirring speed, temperature, air flow, among others that must be monitored before or during the process to ensure the desired CQA. (Zhao, Mao, 2017)

Analytical Method Performance Characteristics (AMPC) are defined to meet the needs of ATP. AMPC may be classified into two categories, according to the source of error: a) systematic (bias) variability, which includes accuracy, specificity, and linearity; and b) random (aleatory) variability, which includes precision, limit of detection, and limit of quantification. Moreover, range and robustness may also be stated into AMPC definition. It is always recommended to incorporate a joint criterion of method characteristics (at least, accuracy and precision) in ATP. Selection of analytical technique (such as chromatographic, spectrophotometric, or microbiological assays) must be driven by ATP and AMPC definitions. (Peraman, Bhadraya, Reddy, 2015; Bhutani et al., 2014)

A schematic diagram of the steps for implementation of pharmaceutical QbD is showed in Figure 1a, including

(a)

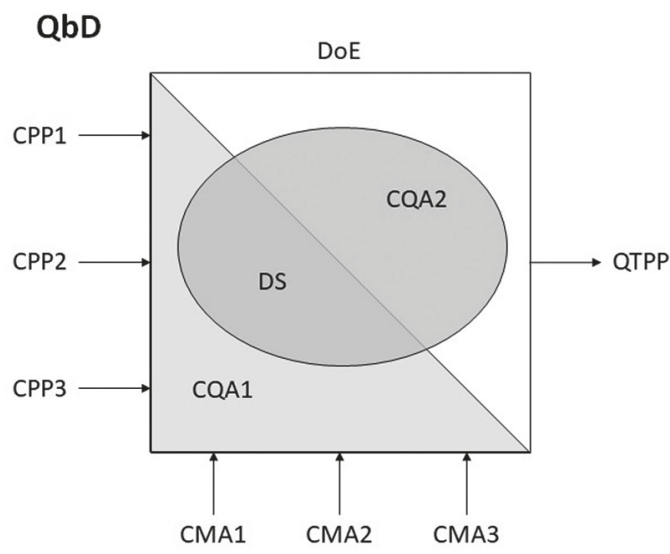

the relationships among CMA, CPA, CQA, Design Space, and QTPP. In addition, the steps for implementation of analytical QbD is showed in Figure 1b, including the relationships among CAP, AMPC, MODR, and ATP.

\section{Risk assessment}

Risk assessment is a systematic process of organizing knowledge information to support decision. There are three essential elements in risk assessment: a) risk identification: systematical use of information to identify potential sources of hazard from historical data, theoretical analysis, and stakeholders' concerns; b) risk analysis: the estimation of risk associated with the identified hazards; and c) risk evaluation: comparison of the estimated risks using quantitative or qualitative scale to determine their significance.

Ishikawa (fishbone) diagram and failure mode and effects analysis (FMEA) are widely used risk assessment tool. Ishikawa diagram is a qualitative risk assessment tool that allows one to identified and classified into broad categories the main sources of hazards. In other words, this helps answering the question "What might be wrong?". FMEA method is often used to perform a quantitative risk assessment, that provides a risk priority number $(\mathrm{RPN}=\mathrm{P} \times \mathrm{S} \times \mathrm{D})$ estimated based on the occurrence probability (P), severity (S), and likelihood of detection (D). FMEA allows one the answer the questions "What is the likely (probability) it will be wrong?" and "What are the consequences (severity)?" (Sangshetti et al., 2017; Zhao, Mao, 2017; Peraman, Bhadraya, Reddy, 2015; Bhutani et al., 2014).

(b)

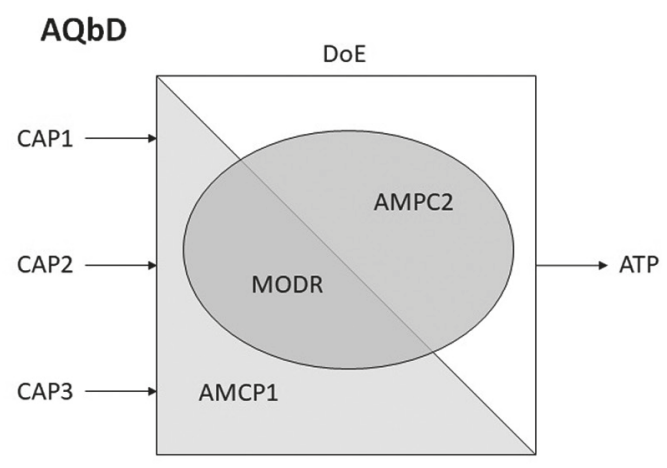

FIGURE 1 - Schematic diagram of the steps for implementation of pharmaceutical QbD (a) and analytical QbD (b). Legend: $\mathrm{CPP}=$ Critical Process Parameter, $\mathrm{CMA}=$ Critical Material Attribute, $\mathrm{CQA}=$ Critical Quality Attribute, $\mathrm{DS}=\mathrm{Design}$ Space, QTPP $=$ Quality Target Product Profile, CAP $=$ Critical Analytical Parameter, AMPC $=$ Analytical Method Performance Characteristic, and ATP = Analytical Target Profile. 


\section{DESIGN OF EXPERIMENTS (DoE)}

DoE is a structured and organized method for determining the relationships between input factors $\left(x_{i}-\right.$ independent variables) affecting one or more output responses $(y-$ dependent variables), through the establishment of mathematical models $\left(y=f\left(x_{i}\right)\right)$.

In DoE approach, the controlled input factors are systematically varied to determine their effects on the output responses, which allows the determination of the most important input factors, the identification of input factors setting leading to optimized output responses, and the elucidation of interactions between input factors.

\section{Selection of experimental design}

Selections of best experimental design should consider several aspects, such as defined objectives, number of input factors and interactions to be studied, and statistical validity and effectiveness of each design. In order to provide a better understand of DoE application, experimental designs may be divided into two types: a) screening designs; and b) optimization designs (Bezerra et al., 2008; Candioti et al., 2014; Politis et al., 2017). Table I provides a summary of screening and optimization designs characteristics, such as number of experiments required, number of levels of input factors, and numbers of factors to be studied.

\section{Screening designs}

Two-level full factorial designs, fractionate factorial designs, and Placket -Burman designs are the most used screening designs because of their cost-effective advantages. These experimental designs allow one to study a wide number of input factors with reduced numbers of experiments. However, they also have some limitations that should be considered in order to provide a better understanding of the effects of input factors on output responses (Bezerra et al., 2008; Candioti et al., 2014; Politis et al., 2017).
Two-level full factorial designs are the most powerful screening designs, once they allow to estimate main effects of input factors and their interactions on output responses. The main limitations of two-level full factorial designs rely on the large number of experiments required, when compared to fractionate factorial designs and Plackett-Burman designs. The number of experiments required for two-level full factorial designs may be calculated as $2^{k}$, where $k$ is the number of input factors to be studied (Bezerra et al., 2008; Candioti et al., 2014; Politis et al., 2017). Two-level full factorial designs matrix for 2, 3, and 4 input factors are presented in Table II.

Fractionate factorial designs are one the most widely used for screening purposes, because these designs enable the evaluation of large number of input factors with a reduced number of experiments required (Bezerra et al., 2008; Candioti et al., 2014; Politis et al., 2017). This may be achieved by fractionating a full factorial $2^{k}$ design into a $2^{k-p}$ design, where $p$ is the number of generators chosen to fractionate the design (Figure 2). For example, when examining four input factors, a half-fraction factorial design $\left(2^{4-1}=8\right.$ experiments $)$ may be adopted. A quarterfraction factorial design $\left(2^{5-2}=8\right.$ experiments $)$ may be adopted to study five input factors, with the same number of experiments.

However, attention should be paid to the estimation of main effects and interaction effects using fractionate factorial designs, because some of them are aliased (or confounded). For example, using a $2^{3-1}$ III fractionate factorial design, the main effect of X3 is aliased with the interaction of X1 and X2 (Figure 3). When adopting a $2^{4-1}$ IV fractionate factorial design, the main effect of $\mathrm{X} 4$ is aliased with $3^{\text {rd }}$ order interaction of X1, X2, and $\mathrm{X} 3$. In fractionate factorial designs with resolution III, main effects are aliased with $2^{\text {nd }}$ order interactions. When using resolution IV designs, main effects are aliased with $3^{\text {rd }}$ order interactions and $2^{\text {nd }}$ order interactions are aliased with $2^{\text {nd }}$ order interactions. Adopting resolution

TABLE I - Summary of screening and optimization designs characteristics, number of experiments, levels, and factors

\begin{tabular}{llccc}
\hline Applications & Experimental design & Experiments & Levels & Factors \\
\hline Screening & Plackett-Burman & $\mathrm{N}$ & 2 & $<\mathrm{N}-1$ \\
& Fractionate factorial & $2^{\mathrm{k}-\mathrm{p}}$ & 2 & $\mathrm{k}>4$ \\
& Two-level full factorial & $2^{\mathrm{k}}$ & 2 & $2<\mathrm{k}<5$ \\
\hline Optimization & Box-Behnken & $2 \mathrm{k}(\mathrm{k}-1)+\mathrm{C}$ & 3 & $3<\mathrm{k}<5$ \\
& Central composite design & $2^{\mathrm{k}}+2 \mathrm{k}+\mathrm{C}$ & 5 & $2 \mathrm{k}<5$ \\
& 3-level factorial & $3^{\mathrm{k}}$ & 3 & $2<\mathrm{k}<3$ \\
\hline
\end{tabular}


TABLE II - Two-level full factorial designs matrix for two $\left(2^{2}\right)$, three $\left(2^{3}\right)$, and four $\left(2^{4}\right)$ input factors (X1 to X4)

\begin{tabular}{|c|c|c|c|c|c|c|c|c|c|c|c|}
\hline \multicolumn{3}{|c|}{$2^{2}$ design matrix } & \multicolumn{4}{|c|}{$2^{3}$ design matrix } & \multicolumn{5}{|c|}{$2^{4}$ design matrix } \\
\hline$\#$ & $\mathrm{X} 1$ & $\mathrm{X} 2$ & $\#$ & $\mathrm{X} 1$ & $\mathrm{X} 2$ & $\mathrm{X} 3$ & $\#$ & $\mathrm{X} 1$ & $\mathrm{X} 2$ & $\mathrm{X3}$ & $\mathrm{X} 4$ \\
\hline 1 & -1 & -1 & 1 & -1 & -1 & -1 & 1 & -1 & -1 & -1 & -1 \\
\hline 2 & -1 & +1 & 2 & -1 & -1 & +1 & 2 & -1 & -1 & -1 & +1 \\
\hline 3 & +1 & -1 & 3 & -1 & +1 & -1 & 3 & -1 & -1 & +1 & -1 \\
\hline 4 & +1 & +1 & 4 & -1 & +1 & +1 & 4 & -1 & -1 & +1 & +1 \\
\hline & & & 5 & +1 & -1 & -1 & 5 & -1 & +1 & -1 & -1 \\
\hline & & & 6 & +1 & -1 & +1 & 6 & -1 & +1 & -1 & +1 \\
\hline & & & 7 & +1 & +1 & -1 & 7 & -1 & +1 & +1 & -1 \\
\hline & & & 8 & +1 & +1 & +1 & 8 & -1 & +1 & +1 & +1 \\
\hline & & & & & & & 9 & +1 & -1 & -1 & -1 \\
\hline & & & & & & & 10 & +1 & -1 & -1 & +1 \\
\hline & & & & & & & 11 & +1 & -1 & +1 & -1 \\
\hline & & & & & & & 12 & +1 & -1 & +1 & +1 \\
\hline & & & & & & & 13 & +1 & +1 & -1 & -1 \\
\hline & & & & & & & 14 & +1 & +1 & -1 & +1 \\
\hline & & & & & & & 15 & +1 & +1 & +1 & -1 \\
\hline & & & & & & & 16 & +1 & +1 & +1 & +1 \\
\hline
\end{tabular}

(a)

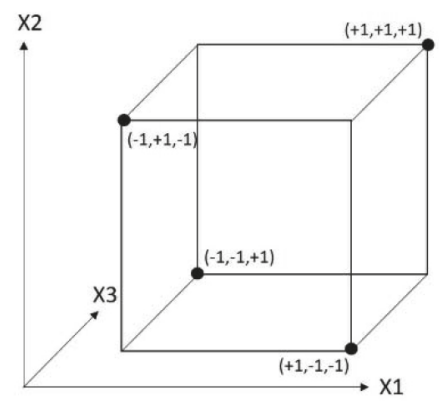

(b)

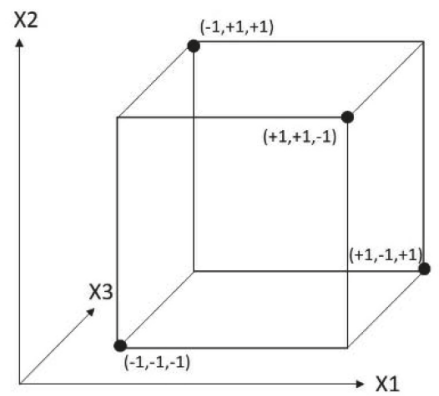

(c)

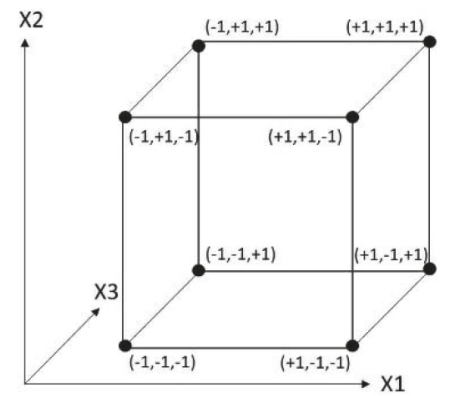

FIGURE 2 - Illustration of a half-fractionate two-level factorial design $\left(2^{3-1}\right.$ III $)$ matrix (a), its complementary matrix (b), and twolevel full factorial design $\left(2^{3}\right)$ matrix (c) for three input factors.

V designs, main effects are aliased with $4^{\text {th }}$ order interactions and $2^{\text {nd }}$ order interactions are aliased with $3^{\text {rd }}$ order interactions. Thus, fractionate factorial designs may not be suitable for assessing the interactions among factors. The resolution of fractionate factorial designs is defined according to the selecting of generators. A summary of fractionate designs matrix were presented in Table III.

Plackett-Burman designs are special types of two-level fractionate factorial designs (resolution III), which allow one to study up to N-1 input factors with $\mathrm{N}$ experiments ( $\mathrm{N}$ should be multiple of 4) (Bezerra et al., 2008; Candioti et al., 2014; Politis et al., 2017). An example of a Plackett-Burman design matrix used to study 11 input factors with 12 experiments is provided in Table IV.

Screening designs are often used in the first step to DoE in order to select the most important input factors and discard the insignificant ones. Pareto charts are useful tools to achieve this purpose (Figure 3), because they allow to put the input factors (and their interactions) in order of importance. For example, based on Pareto chart presented in Figure 2a we conclude that input factor X1 is the most important, followed by factors X3 and X2, respectively. When a fractionate factorial design was adopted, attention should be paid to analyze Pareto chart. In other words, 
(a)

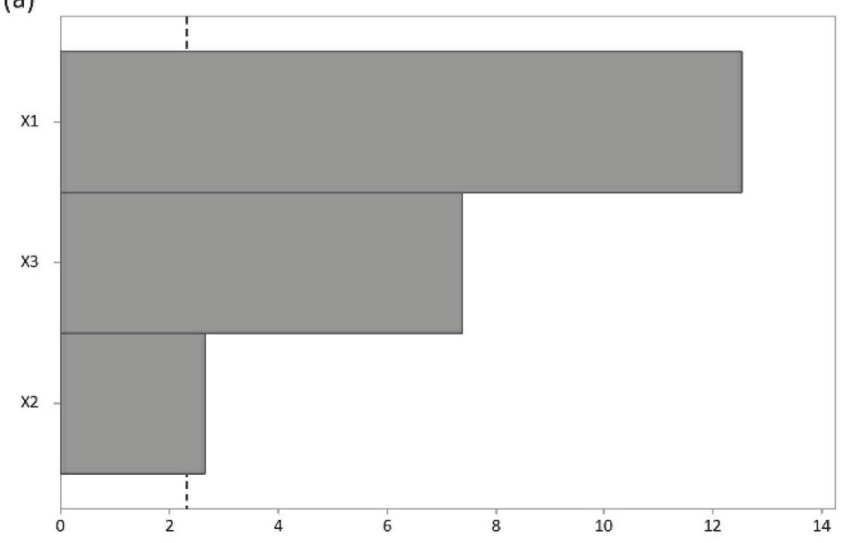

(b)

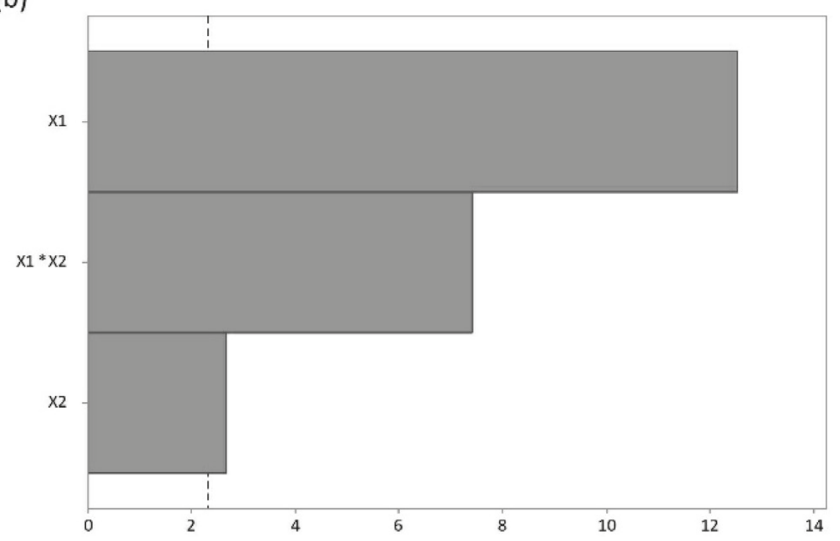

FIGURE 3 - Pareto charts representation for main effects (X1, $\mathrm{X} 2$, and X3) of input factors (a), and main effects (X1, and X2) and interaction effects $(\mathrm{X} 1 * \mathrm{X} 2)$ of input factors $(\mathrm{b})$. Main effect of X3 (a) is aliased with the interaction of X1 and X2 (b).

main effect of input factor X3 (Figure 3a) was aliased with the interaction of factors $\mathrm{X} 1$ and $\mathrm{X} 2$ (Figure $3 \mathrm{~b}$ ). For instance, consider that during the development of a chromatographic method, one wants to explain the resolution between two peaks as functions of the $\mathrm{pH}$ of mobile phase (X1), amount of organic solvent in mobile phase (X2), and flow rate (X3). Based on Pareto chart showed in Figure 3a, one may conclude that the flow rate is a critical analytical parameter. However, the flow rate is aliased (or confounded) with the interaction between $\mathrm{pH}$ and amount of organic solvent in mobile phase (X3 = $\mathrm{X} 1 \mathrm{x} \mathrm{X} 2$ ). This conclusion was wrongly assumed because Pareto chart showed in Figure 3a was obtained using a fractionate factorial design with resolution III. When using a full factorial, flow rate will not be aliased (confounded) with the interaction between $\mathrm{pH}$ and amount of organic solvent in mobile phase, which is evidenced in Pareto chart showed in Figure $3 b$.

However, Pareto charts does not provide information of how the output responses are affect by varying input factor level. This information may be provided by a main effects and interactions plots (Figure 4). For example, output response increases by varying the input factor X1 from low (-1) to high $(+1)$ level, while output response decreases by varying the input factor X2 from low (-1) to high (+1) level (Figure 4a). An advantage of DoE approach over the OFAT experimentation relies on the elucidation of interactions between input factors. For example, in Figure 4b, the output response increases significantly by varying the input factor X1 from low (-1) to high (+1) level with X2 fixed at low level (-1 - grey dots and line), while output response remains almost constant by varying the input factor X1 from low (-1) to high $(+1)$ level with X2 fixed at high level $(+1-$ black dots and line). Interaction effects plots is useful to identified synergism or antagonism between input factors on output responses.

TABLE III - Half- and quarter-fractionate two-level factorial designs matrix for three $\left(2^{3-1}{ }_{\text {III }}\right)$, four $\left(2^{4-1}{ }_{\text {IV }}\right)$, and five $\left(2^{5-2}\right)$ inf input factors (X1 to X5)

\begin{tabular}{|c|c|c|c|c|c|c|c|c|c|c|c|c|c|c|}
\hline \multicolumn{4}{|c|}{$2^{3-1}$ III design matrix ${ }^{* 1}$} & \multicolumn{5}{|c|}{$2^{4-1}$ dV design matrix ${ }^{* 2}$} & \multicolumn{6}{|c|}{$2^{2^{5-2}}$ design matrix ${ }^{* 3}$} \\
\hline$\#$ & $\mathrm{X} 1$ & $\mathrm{X} 2$ & $\mathrm{X3}$ & $\#$ & $\mathrm{X1}$ & $\mathrm{X} 2$ & $\mathbf{X 3}$ & $\mathrm{X} 4$ & $\#$ & $\mathrm{X} 1$ & $\mathrm{X} 2$ & $\mathrm{X3}$ & $\mathrm{X4}$ & $\mathrm{X5}$ \\
\hline 1 & -1 & -1 & +1 & 1 & -1 & -1 & -1 & -1 & 1 & -1 & -1 & -1 & +1 & +1 \\
\hline 2 & -1 & +1 & -1 & 2 & +1 & -1 & -1 & +1 & 2 & 1 & -1 & -1 & -1 & -1 \\
\hline 3 & +1 & -1 & -1 & 3 & -1 & +1 & -1 & +1 & 3 & -1 & 1 & -1 & -1 & +1 \\
\hline 4 & +1 & +1 & +1 & 4 & +1 & +1 & -1 & -1 & 4 & 1 & 1 & -1 & +1 & -1 \\
\hline & & & & 5 & -1 & -1 & +1 & +1 & 5 & -1 & -1 & 1 & +1 & -1 \\
\hline & & & & 6 & +1 & -1 & +1 & -1 & 6 & 1 & -1 & 1 & -1 & +1 \\
\hline & & & & 7 & -1 & +1 & +1 & -1 & 7 & -1 & 1 & 1 & -1 & -1 \\
\hline & & & & 8 & +1 & +1 & +1 & +1 & 8 & 1 & 1 & 1 & +1 & +1 \\
\hline
\end{tabular}

${ }^{{ }_{1}} \mathrm{X} 3=\mathrm{X} 1 \times \mathrm{X} 2 /{ }^{* 2} \mathrm{X} 4=\mathrm{X} 1 \times \mathrm{X} 2 \times \mathrm{X} 3 /{ }^{* 3} \mathrm{X} 4=\mathrm{X} 1 \times \mathrm{X} 2$ and $\mathrm{X} 5=\mathrm{X} 1 \times \mathrm{X} 3$ 
Design of Experiments (DoE) applied to Pharmaceutical and Analytical Quality by Design (QbD)

TABLE IV - Plackett-Burman design matrix to study 11 input factors (X1 to X11) with 12 experiments

\begin{tabular}{cccccccccccc}
\hline$\#$ & $\mathbf{X 1}$ & $\mathbf{X 2}$ & $\mathbf{X 3}$ & $\mathbf{X} 4$ & $\mathbf{X 5}$ & $\mathbf{X 6}$ & $\mathbf{X 7}$ & $\mathbf{X 8}$ & $\mathbf{X 9}$ & $\mathbf{X 1 0}$ & $\mathbf{X 1 1}$ \\
\hline 1 & +1 & -1 & +1 & -1 & -1 & -1 & +1 & +1 & +1 & -1 & +1 \\
2 & +1 & +1 & -1 & +1 & -1 & -1 & -1 & +1 & +1 & +1 & -1 \\
3 & -1 & +1 & +1 & -1 & +1 & -1 & -1 & -1 & +1 & +1 & +1 \\
4 & +1 & -1 & +1 & +1 & -1 & +1 & -1 & -1 & -1 & +1 & +1 \\
5 & +1 & +1 & -1 & +1 & +1 & -1 & +1 & -1 & -1 & -1 & +1 \\
6 & +1 & +1 & +1 & -1 & +1 & +1 & -1 & +1 & -1 & -1 & -1 \\
7 & -1 & +1 & +1 & +1 & -1 & +1 & +1 & -1 & +1 & -1 & -1 \\
8 & -1 & -1 & +1 & +1 & +1 & -1 & +1 & +1 & -1 & +1 & -1 \\
9 & -1 & -1 & -1 & +1 & +1 & +1 & -1 & +1 & +1 & -1 & +1 \\
10 & +1 & -1 & -1 & -1 & +1 & +1 & +1 & -1 & +1 & +1 & -1 \\
11 & -1 & +1 & -1 & -1 & -1 & +1 & +1 & +1 & -1 & +1 & +1 \\
12 & -1 & -1 & -1 & -1 & -1 & -1 & -1 & -1 & -1 & -1 & -1 \\
\hline
\end{tabular}

(a)

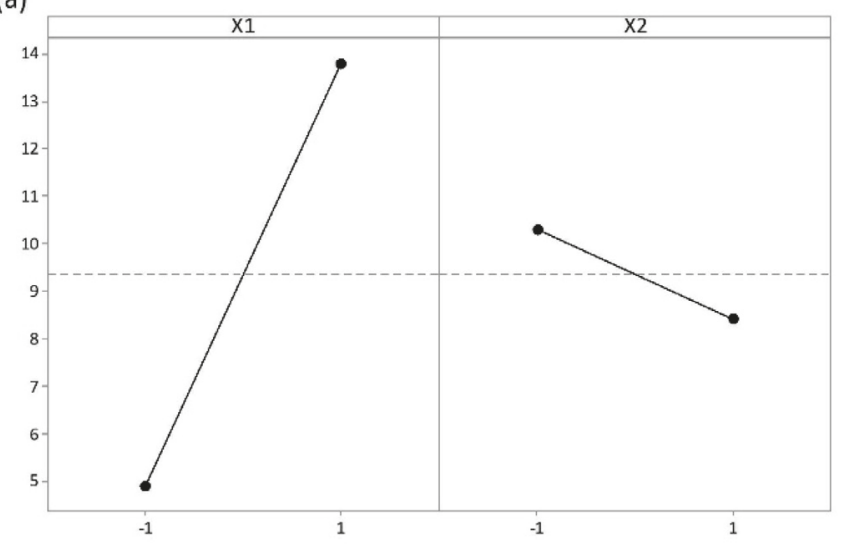

(b)

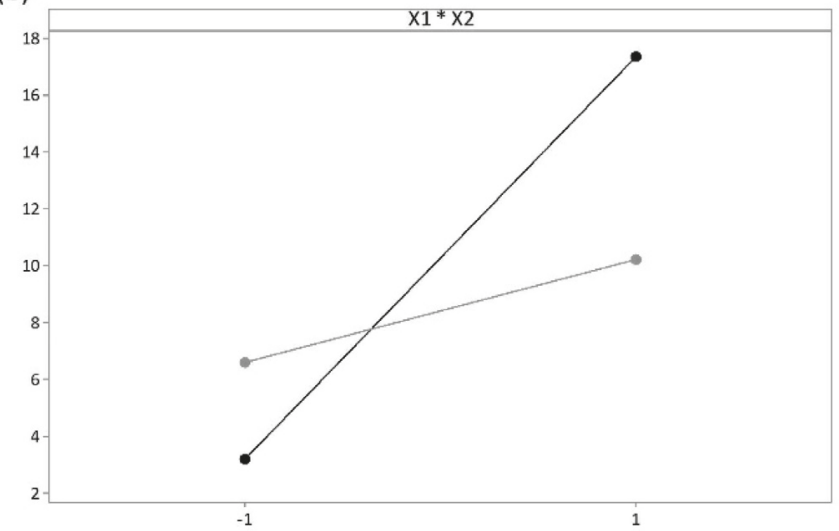

FIGURE 4 - Main effects (a) and interaction (b) plots of input factors $\mathrm{X} 1$ and $\mathrm{X} 2$.

\section{Optimization designs}

Three-level full factorial designs, central composite designs, and Box-Behnken designs are the most used optimization designs because they allow modeling complex response surface. One of the most important limitations of screening designs rely on the fact that they only allow modeling $1^{\text {st }}$ order (linear) response surface, because they have only two level for each input factor. Optimization designs uses 3 to 5 levels of each input factors, which allow modeling $2^{\text {nd }}$ order (quadratic) response surface (Bezerra et al., 2008; Candioti et al., 2014; Politis et al., 2017). However, due to the increased number of experiments required, they are usually used to study a reduced number of input factors (Table I).

Three-level full factorial design are often used only when two or three input factors need to be study, because an increased number of experiments is required. The number of experiments required may be calculated as $3^{k}$, where $k$ is the number of input factors to be studied (Bezerra et al., 2008; Candioti et al., 2014; Politis et al., 2017). For example, a three-level full factorial design for three input factors requires $3^{3}=27$ experiments (Table V). A 3D spatial representation of factorial design is provided in Figure 5a.

Central composite designs (CCD) are one of the most used optimization designs because they use 5 level of each input factor with a reduced number of experiments required, when compared to three-level full factorial design (Bezerra et al., 2008; Candioti et al., 2014; Politis et al., 2017). A 3D spatial representation of CCD for three input factors is provided in Figure 5b. This design consists of the following parts: a) the factorial design points (black dots); b) the axial points (grey dots); and c) the center point (white dots). CCD matrix is also presented in Table $\mathrm{V}$, with the factorial design points (experiments 1-8), the axial points (experiments 9-14), and the central point (experiments 15-20 - 6 replicas). 
TABLE V - Three-level full factorial design ( $\left.3^{3}\right)$, central composite design (CCD), and Box-Behnken design matrix for three input factors (X1, X2, and X3)

\begin{tabular}{|c|c|c|c|c|c|c|c|c|c|c|c|}
\hline \multicolumn{4}{|c|}{$3^{3}$ design matrix } & \multicolumn{4}{|c|}{ Central composite design matrix } & \multicolumn{4}{|c|}{ Box-Behnken matrix } \\
\hline$\#$ & $\mathbf{X 1}$ & $\mathrm{X} 2$ & $\mathbf{X 3}$ & $\#$ & $\mathrm{X} 1$ & $\mathrm{X} 2$ & $\mathbf{X 3}$ & $\#$ & $\mathbf{X 1}$ & $\mathrm{X} 2$ & $\mathbf{X 3}$ \\
\hline 1 & -1 & -1 & -1 & 1 & -1 & -1 & -1 & 1 & -1 & -1 & 0 \\
\hline 2 & -1 & -1 & 0 & 2 & +1 & -1 & -1 & 2 & +1 & -1 & 0 \\
\hline 3 & -1 & -1 & +1 & 3 & -1 & +1 & -1 & 3 & -1 & +1 & 0 \\
\hline 4 & -1 & 0 & -1 & 4 & +1 & +1 & -1 & 4 & +1 & +1 & 0 \\
\hline 5 & -1 & 0 & 0 & 5 & -1 & -1 & +1 & 5 & -1 & 0 & -1 \\
\hline 6 & -1 & 0 & +1 & 6 & +1 & -1 & +1 & 6 & +1 & 0 & -1 \\
\hline 7 & -1 & +1 & -1 & 7 & -1 & +1 & +1 & 7 & -1 & 0 & +1 \\
\hline 8 & -1 & +1 & 0 & 8 & +1 & +1 & +1 & 8 & +1 & 0 & +1 \\
\hline 9 & -1 & +1 & +1 & 9 & $-1,68$ & 0 & 0 & 9 & 0 & -1 & -1 \\
\hline 10 & 0 & -1 & -1 & 10 & $+1,68$ & 0 & 0 & 10 & 0 & +1 & -1 \\
\hline 11 & 0 & -1 & 0 & 11 & 0 & $-1,68$ & 0 & 11 & 0 & -1 & +1 \\
\hline 12 & 0 & -1 & +1 & 12 & 0 & $+1,68$ & 0 & 12 & 0 & +1 & +1 \\
\hline 13 & 0 & 0 & -1 & 13 & 0 & 0 & $-1,68$ & 13 & 0 & 0 & 0 \\
\hline 14 & 0 & 0 & 0 & 14 & 0 & 0 & $+1,68$ & 14 & 0 & 0 & 0 \\
\hline 15 & 0 & 0 & +1 & 15 & 0 & 0 & 0 & 15 & 0 & 0 & 0 \\
\hline 16 & 0 & +1 & -1 & 16 & 0 & 0 & 0 & & & & \\
\hline 17 & 0 & +1 & 0 & 17 & 0 & 0 & 0 & & & & \\
\hline 18 & 0 & +1 & +1 & 18 & 0 & 0 & 0 & & & & \\
\hline 19 & +1 & -1 & -1 & 19 & 0 & 0 & 0 & & & & \\
\hline 20 & +1 & -1 & 0 & 20 & 0 & 0 & 0 & & & & \\
\hline 21 & +1 & -1 & +1 & & & & & & & & \\
\hline 22 & +1 & 0 & -1 & & & & & & & & \\
\hline 23 & +1 & 0 & 0 & & & & & & & & \\
\hline 24 & +1 & 0 & +1 & & & & & & & & \\
\hline 25 & +1 & +1 & -1 & & & & & & & & \\
\hline 26 & +1 & +1 & 0 & & & & & & & & \\
\hline 27 & +1 & +1 & +1 & & & & & & & & \\
\hline
\end{tabular}

(a)

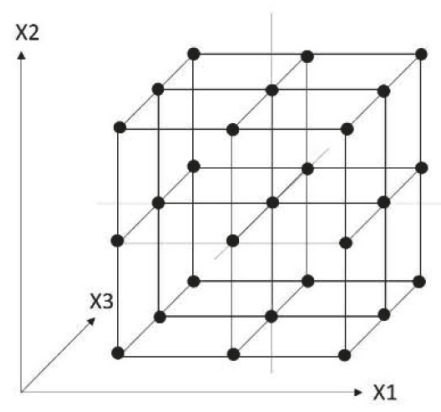

(b)

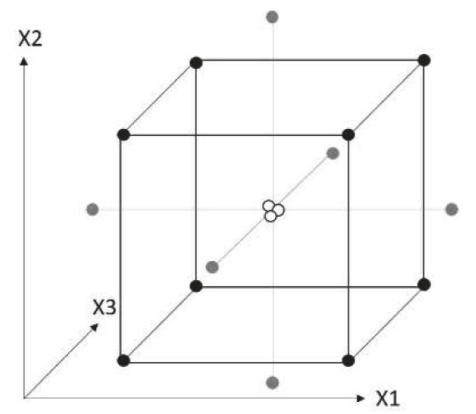

(c)

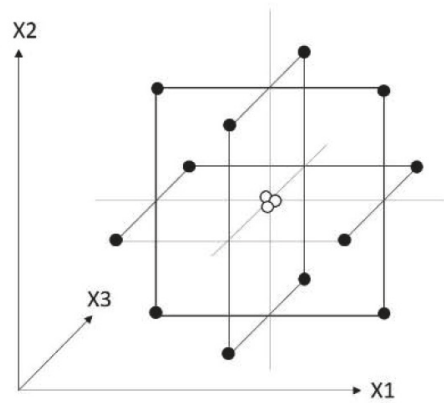

FIGURE 5 - Illustration of three-level full factorial design ( $3^{3}$ ) matrix (a), central composite design (CCD) matrix (b), and BoxBehnken design matrix (c) for three input factors. 
Box-Behnken design are special types of three-level fractionate factorial designs, which allows modeling $1^{\text {st }}$ and $2^{\text {nd }}$ order response surfaces. These designs are more cost-effective than three-level full factorial designs, particularly for large number of input factors (Bezerra et al., 2008; Candioti et al., 2014; Politis et al., 2017). We can see that all points used in Box-Behnken designs (Figure 5c) were selected from the $3^{3}$ full factorial design (Figure 5a). The Box-Behnken matrix was also provided in Table V.

The simplest model which can be adjusted is based on a linear function. This model may be adjusted based on the results obtained from at least a fractionate factorial design (resolution IV or higher), if the output responses are well fitted to Equation 1.

$$
y=\beta_{0}+\sum_{i}^{k} \beta_{i} \times x_{i}+\varepsilon
$$

Thus, the output response should have a linear response surface, as presented in Figure 6a.

To evaluate interactions between input factors, at least a two-level full factorial design should be adopted. The model can be adjusted based on a linear + interaction function, if the output response is well fitted to the Equation 2.

$$
y=\beta_{0}+\sum_{i}^{k} \beta_{i} \times x_{i}+\sum_{i j}^{k} \beta_{i j} \times x_{i} \times x_{j}+\varepsilon
$$

The response surface obtained using a linear + interaction function is presented in Figure $6 \mathrm{~b}$.

The main advantage of optimization designs relies on the possibility of modeling $2^{\text {nd }}$ order response surfaces, because they have 3 to 5 level for each input factor. In other words, these designs allow one the assess curvature of response surface. The model can be adjusted based on a linear + quadratic function, if the output response is well fitted to the Equation 3.

$$
y=\beta_{0}+\sum_{i}^{k} \beta_{i} \times x_{i}+\sum_{i}^{k} \beta_{i i} \times x_{i}^{2}+\varepsilon
$$

Thus, the output response should have a curvature response surface, due to the presense of quadratic terms in regression model. The response surface obtained using a linear + quadratic function is presented in Figure $6 c$.

Finally, it may be necessary to adopt a full model, with linear + interaction + quadratic terms. The model can be adjusted based on a full model function, if the output response is well fitted to the Equation 4.

$y=\beta_{0}+\sum_{i}^{k} \beta_{i} \times x_{i}+\sum_{i j}^{k} \beta_{i j} \times x_{i} \times x_{j}+\sum_{i}^{k} \beta_{i i} \times x_{i}^{2}+\varepsilon$
The response surface obtained using a linear + interaction + quadratic function is presented in Figure $6 \mathrm{~d}$.

Mathematical model should be selected based on the application of Analysis of Variance (ANOVA). The main idea of ANOVA is to compare the variability due to treatment (varying the level of input factors) with the variability due to residual error. From this comparison, it is possible to evaluate the significance of the regression model (Table VI). Regression analysis is valid only if the residues (square of the difference between response predicted by mathematical model and experimental response) present normal distribution and homoscedasticity. When necessary, a Box-Cox transformation (for example, $\ln$ transformation $-\lambda=0$ ) of output response may be used to improve normality and homoscedasticity of residues. (Bezerra et al., 2008; Candioti et al., 2014; Politis et al., 2017).

Based on ANOVA, we can decide to include or to exclude the coefficients of linear terms (for example, $\mathrm{X} 1, \mathrm{X} 2$, and X3), interaction terms (for example, X1X2, $\mathrm{X} 1 \mathrm{X} 3$, and $\mathrm{X} 2 \mathrm{X} 3$ ), and quadratic terms (for example $\mathrm{X}^{2}, \mathrm{X}^{2}$, and $\mathrm{X} 3^{2}$ ). This decision is based on $\mathrm{p}$-values for each coefficient regression term. Usually, a coefficient regression term should be included in regression model when its p-value is lower than 0.05 . In other words, when the coefficient regression term is significantly different from 0 . When the regression coefficient term is not different from 0 ( $\mathrm{p}$-value $>0.05)$, it indicates that the output response is not affect by varying the input factor levels. Thus, this coefficient regression term may be excluded from the regression model.

Multiple regression model adjustment should be assess based on determination coefficients $\left(\mathrm{R}^{2}, \mathrm{R}^{2}\right.$-adj, and $\mathrm{R}^{2}$-pred). Determination coefficient $\left(\mathrm{R}^{2}\right)$ is the proportion of the variance in the output response that is predicted from the input factors. In other words, how much of output response (Y) is explained by the input factors (Xs). However, $\mathrm{R}^{2}$ will always increase by adding new terms to the regression model. Thus, it is not a good way to compared regression models with different number of terms (for example, compare a linear model with a full model). The adjusted $R^{2}\left(R^{2}\right.$-adj) is a modified version of $\mathrm{R}^{2}$ which is adjusted for the number of terms in regression model. The $\mathrm{R}^{2}$-adj increases only if the new term improves the regression model. On the other hand, it decreases when the term does not improve the regression model. Thus, $\mathrm{R}^{2}$-adj allow one to compare the explanatory power of regression models that contain different number of terms. Predictive $\mathrm{R}^{2}$ ( $\mathrm{R}^{2}$-pred) indicates how well a regression model predicts output responses for new observations. $\mathrm{R}^{2}$-pred is calculated by systematically removing each 
observation from the data set, estimating the regression equation, and determining how well the model predicts the removed observation. $\mathrm{R}^{2}$-adj and $\mathrm{R}^{2}$-pred are always lower than $\mathrm{R}^{2}$.

In addition, variability due to lack-of-fit of regression model should be compared to the variability due to random pure error in order to assess regression model adjustment

(a)

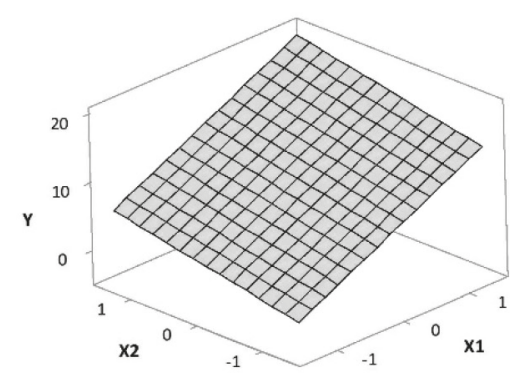

(b)

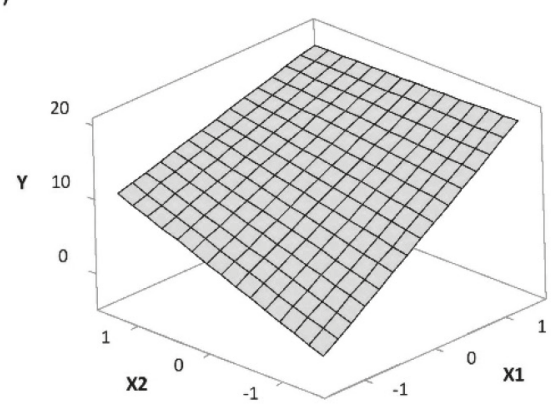

(c)

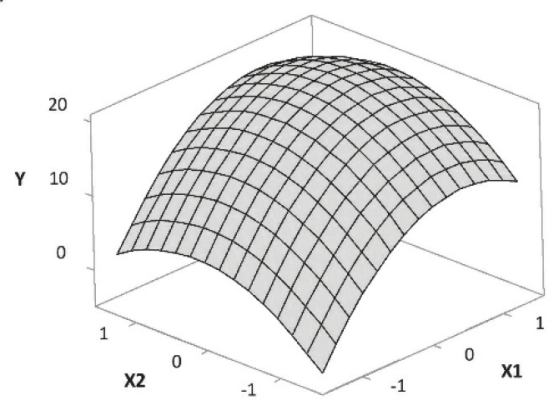

(d)

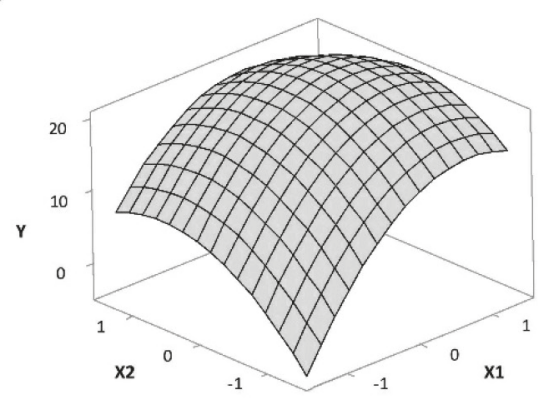

(Table VI). Regression model is poorly adjusted when the error provided by regression model lack-of-fit is significantly higher than random pure error ( $p$-value $<$ $0.05)$. On the other hand, when the error provided by regression model lack-of-fit is significantly lower than random pure error ( $p$-value $>0.05$ ), it indicates that the regression model is well fitted. It is important to notice
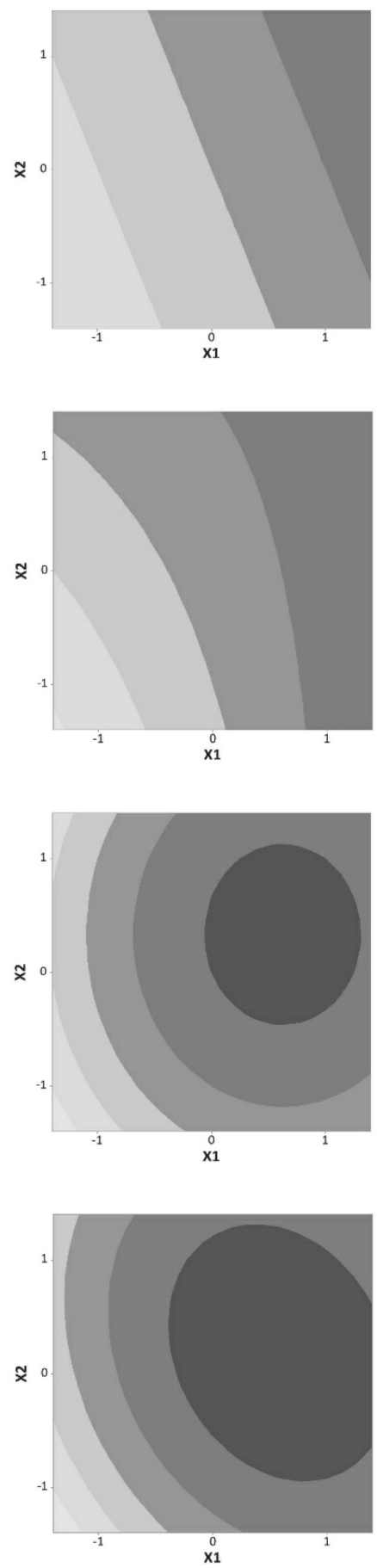

FIGURE 6 - Response surface and counter plots for linear (a), linear + interaction (b), linear + quadratic, and full (d) model functions. 
TABLE VI - Analysis of variance (ANOVA) used in multiple regression analysis to evaluate regression significance, residual error, and lack-of-fit adjustment

\begin{tabular}{|c|c|c|c|c|}
\hline Source & d.f. & SS & MS & $\mathbf{F}$ \\
\hline Regression & $p-1$ & $\sum_{i}^{m} \sum_{j}^{n_{1}}\left(\hat{y}_{i}-\underline{y}\right)^{2}$ & $\frac{S S_{\text {Regression }}}{p-1}$ & $\frac{M S_{\text {Regression }}}{M S_{\text {Residuals }}}$ \\
\hline Residuals & $n-p$ & $\sum_{i}^{m} \sum_{j}^{n_{1}}\left(y_{i j}-\hat{y}_{i}\right)^{2}$ & $\frac{S S_{\text {Residuals }}}{n-p}$ & \\
\hline Lack-of-fit & $m-p$ & $\sum_{i}^{m} \sum_{j}^{n_{1}}\left(\hat{y}_{i}-\underline{y}_{i}\right)^{2}$ & $\frac{S S_{\text {Lack-of-fit }}}{m-p}$ & $\frac{M S_{\text {Lack-of-fit }}}{M S_{\text {Pureerror }}}$ \\
\hline Pure error & $n-m$ & $\sum_{i}^{m} \sum_{j}^{n_{i}}\left(y_{i j}-\underline{y}_{i}\right)^{2}$ & $\frac{S S_{\text {Pureerror }}}{n-m}$ & \\
\hline Total & $n-1$ & $\sum_{i}^{m} \sum_{j}^{n_{i}}\left(y_{i j}-\underline{y}\right)^{2}$ & & \\
\hline
\end{tabular}

Legend: d.f. $=$ degrees of freedom, $\mathrm{SS}=$ sum of squares, $\mathrm{MS}=$ mean square, $\mathrm{F}=$ F-test statistics.

that lack-of-fit error can be estimated only when the experimental design includes replicas, usually for central point.

\section{Defining Design Space (DS) / Method Operable Design Region (MODR)}

Design Space (DS) is a multidimensional combination and interaction of input factors (usually CMA and CPP) that have been proofed to provide assurance of quality, and consequently, safety and efficacy. Moving the input factors within the design space regions is not considered a modification subject to notification, which ensure regulatory flexibility (Yu et al., 2014).

In analytical QbD, Method Operable Design Region (MODR) (also called analytical design space) is the multidimensional combination and interaction of analytical conditions (input factors; for example, chromatographic conditions) that have been demonstrated to provide assurance performance of analytical method (output response; for example, resolution between peaks) (Bhutani et al., 2014).

Design space region may be obtained by graphical optimization from overlaid counter plots of output responses (Ys) as functions of input factors (Xs) (Figure 7). Alternatively, multiple response optimization may be estimated by numerical technics of desirability functions. Desirability functions are usually design to achieve different criteria, for example to maximize, minimize, and target optimization of the output responses (Figure 8) (Candioti et al., 2014). (a)

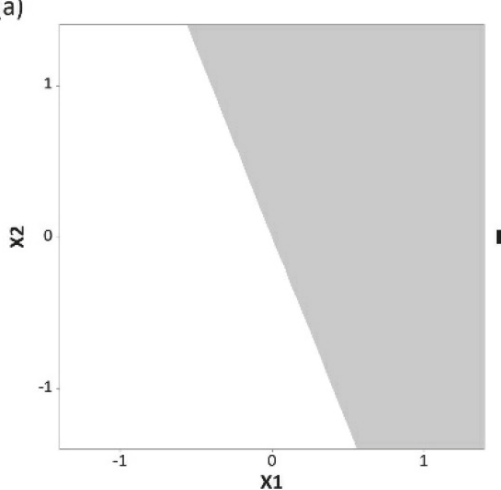

(b)

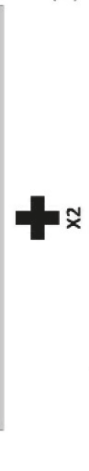

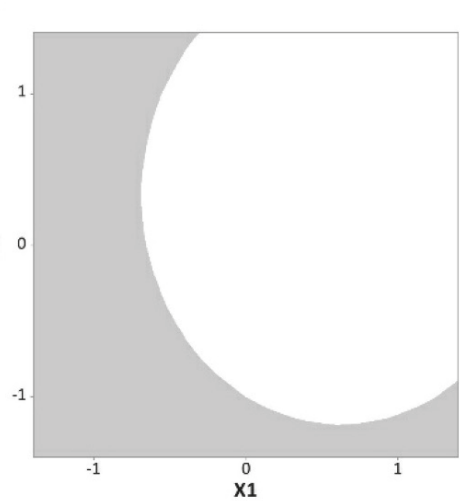

(c)

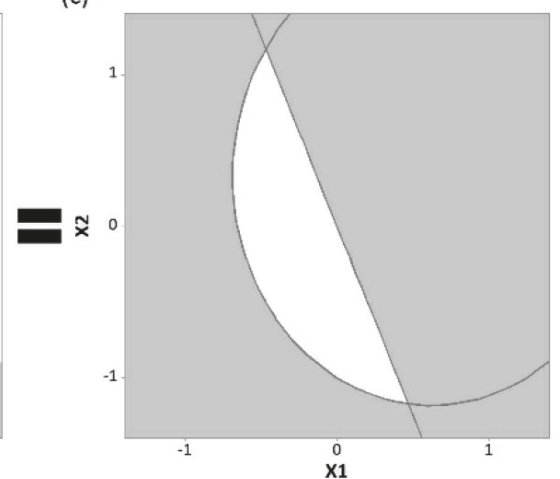

FIGURE 7 - Design space (white regions) obtained from counter plot of output response Y1 (a), from counter plot of output response Y2 (b), and from overlaid counter plot of output responses Y1 and Y2 (c) as function of input factors X1 and X2. 
(a)

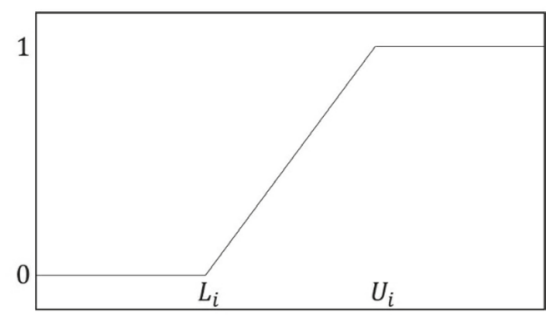

(b)

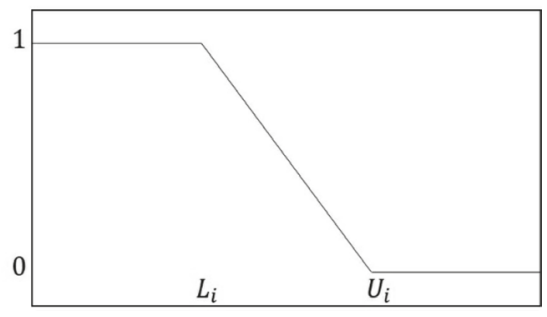

(c)

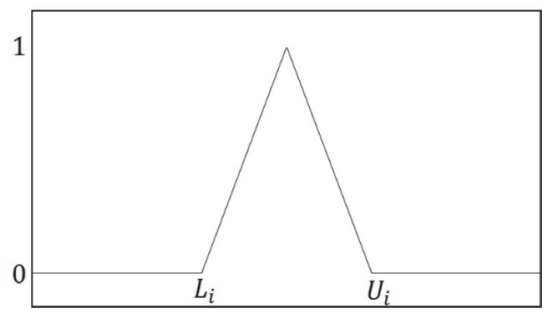

FIGURE 8 - Desirability functions to maximize (a), minimize (b), and target optimization, usually used in multiple response optimization.

\section{Implementing control strategy and Continuous improvement}

Control strategy is required to ensure that critical material attributes (CMA) and critical process parameters (CPP) are within the expected limits. Obviously, control space should be within the design space (Sangshetti et al., 2017). Analytical Process Technology (PAT) is an important tool in control strategy implementation, once it enables real-time release testing and provides an increased level of quality assurance compared to conventional endproduct testing. However, PAT is not the only way to implement real-time release. Predictive models may also be used as an alternative to conventional release testing (Yu et al., 2014; Zhang, Mao, 2017).

In analytical $\mathrm{QbD}$, control strategy is derived from the data collected during method development and validation, which enables to predict the ability of method to meet analytical target profile (ATP) (Peraman, Bhadraya, Reddy, 2015). Continuous monitoring of method performance allows to detect, identified, and address out-of-trend performance of the analytical method (Peraman, Bhadraya, Reddy, 2015).

The QbD approach allows the continuous improvement throughout the lifecycle of pharmaceutical product and analytical method, including to reduce product variability, to improve process performance, to reduce out-of-specification results, to improve analytical performance, among others.

\section{APPLICATIONS OF DESIGN OF EXPERIMENTS IN QbD AND AQbD}

Quality by Design approach was accepted by FDA in 2004 and described in 'pharmaceutical cGMPs for $21^{\text {st }}$ century - a risk-based approach'. International conference on harmonization (ICH) Q8 pharmaceutical development, Q9 quality risk assessment, and Q10 pharmaceutical quality system provide detailed requirements regarding pharmaceutical product quality. $\mathrm{QbD}$ and $\mathrm{DoE}$ approaches help to implement ICH/Q8 and ICH/Q9.

Since QbD approach was accepted by FDA, DoE has been widely employed in order to provide a complete understanding of the product and its manufacturing process. Many applications of DoE used for screening and optimization purposes of pharmaceutical products and their manufacturing processes may be found in the literature. Several input factors (independent variables), such as excipient concentrations, stirring time, stirring speed, temperature, pressure, among other may be screened and optimized using DoE. Studied output responses (dependent variables) included particle size, entrapment efficiency, dissolution rate, among other. Some examples of DoE applications were showed in Table VII.

Application of screening designs in pharmaceutical QbD allow to identify the critical material attributes (CMAs) and critical process parameters (CPPs) (independent variables) affecting the critical quality attributes (CQAs) (dependent variables) and, therefore, the quality target product profile (QTPP). In addition, optimizing design and surface response methodology and multiple response optimization allow to define a design space region in which CQAs and QTPP are attended. The adoption of a design space region based on product and process understanding allow regulatory flexibility, because changes within the design space region do not require prior regulatory approval.

Recently, DoE has been used in the rational development and optimization of analytical methods. Culture media composition, mobile phase composition, flow rate, time of incubation are examples of input factors (independent variables) that may the screened and optimized using DoE. Several output responses (dependent variables), such as retention time, resolution between peaks, microbial growth, among other responses were found in literature. Table VIII shows some applications 
TABLE VII - Examples of DoE applications for pharmaceutical development, experimental design adopted, independent variables (input factors - Xs), and dependent variables (output responses - Ys)

\begin{tabular}{|c|c|}
\hline $\begin{array}{l}\text { Experimental } \\
\text { design }\end{array}$ & Independent variables (Xs) \\
\hline $\begin{array}{l}\text { Fractionate factorial } \\
\text { design }\end{array}$ & $\begin{array}{l}\text { Indomethacin concentration, stabilizer type, } \\
\text { stabilizer concentration, processing temperature, } \\
\text { and homogenization pressure }\end{array}$ \\
\hline $\begin{array}{l}\text { Fractionate factorial } \\
\text { design and central } \\
\text { composite design }\end{array}$ & $\begin{array}{l}\text { Inlet air temperature, air flow rate and binder } \\
\text { spray rate during the sprying phase }\end{array}$ \\
\hline $\begin{array}{l}\text { 3-level factorial } \\
\text { design }\end{array}$ & $\begin{array}{l}\text { Span } 60 \text { : Sodium lauryl sulfate ratio, organic } \\
\text { : aqueous phase volume ratio, and polymer } \\
\text { concentration }\end{array}$ \\
\hline $\begin{array}{l}\text { Box-Behnken } \\
\text { design }\end{array}$ & $\begin{array}{l}\text { Sodium alginate percentage, chitosan percentage, } \\
\text { and calcium chloride percentage }\end{array}$ \\
\hline $\begin{array}{l}\text { 2-level factorial } \\
\text { design }\end{array}$ & $\begin{array}{l}\text { Amount of oil (capmul MCM), amount of } \\
\text { surfactant (tween } 80 \text { ), and amount of cosolvent } \\
\text { (Transcutol HP) }\end{array}$ \\
\hline
\end{tabular}

\begin{tabular}{ll}
\hline $\begin{array}{l}\text { Multiple response } \\
\text { optimization }\end{array}$ & $\begin{array}{l}\text { Concentrations of imidazolidinyl urea, } \\
\text { methyparaben, propylparaben, and EDTA in } \\
\text { cosmetic formulations }\end{array}$
\end{tabular}

Central composite Percentage of HPMC, percentage of glycerol, design and drying temperature

\begin{tabular}{ll}
\hline $\begin{array}{l}\text { 2-level factorial } \\
\text { design }\end{array}$ & $\begin{array}{l}\text { Kneading temperature, impeller speed, liquid } \\
\text { addition, extrusion speed, spheronizer speed, and } \\
\text { spheronization time }\end{array}$ \\
\hline $\begin{array}{l}\text { Box-Behnken } \\
\text { design }\end{array}$ & Lipid, lipid oil, and surfactand phase \\
\hline $\begin{array}{l}\text { Central composite } \\
\text { design }\end{array}$ & $\begin{array}{l}\text { Combination ratio of Eudragit }{ }^{R} \text { FS-30D / } \\
\text { Eudragit@ RS-PO, PVA concentration in } \\
\text { external phase, and NaCl concentration on } \\
\text { external phase }\end{array}$ \\
\hline $\begin{array}{l}\text { 2-level factorial } \\
\text { design }\end{array}$ & $\begin{array}{l}\text { Surfactant concentration, solid/liquid lipid } \\
\text { ration, and ultrasonication time }\end{array}$
\end{tabular}

\begin{tabular}{ll}
\hline Box-Behnken & $\begin{array}{l}\text { Amount of surfactant/cosurfactant mixture, } \\
\text { design }\end{array}$ \\
& $\begin{array}{l}\text { processing pressure and number of } \\
\text { homogenization cycles }\end{array}$
\end{tabular}

\begin{tabular}{ll}
\hline $\begin{array}{l}\text { 2-level factorial } \\
\text { design }\end{array}$ & $\begin{array}{l}\text { Concentrations of ethylhexyl triazone, } \\
\text { bemotrizinol, and ferulic acid in multifunctional } \\
\text { sunscreens }\end{array}$ \\
\hline $\begin{array}{l}\text { 3-level factorial } \\
\text { design }\end{array}$ & Poloxamer 188, and acetone to methanol ratio \\
\hline $\begin{array}{l}\text { 3-level factorial } \\
\text { design }\end{array}$ & $\begin{array}{l}\text { Oil to surfactant/cosurfactant ratio and } \\
\text { concentration of gellan gum }\end{array}$
\end{tabular}

2-level factorial Hydration temperature, stirring speed, and design stirring time

\section{Dependent variables (Ys)}

Particle size distribution, zeta potential, and physical form (XRD) of nanosuspensions

Moisture of granules and flow through an orifice of the granules obtained by fluid bed granulation

Emulsion phase stability, viscosity, and conductivity

Maximum drug encapsulation, particle size and drug release of cefpodoxime proxetil chitosanalginate beads

Globule size, span, equilibrium solubility of cilostazol, zeta potential, and dissolution efficiency at $30 \mathrm{~min}$ of lipid based nanoemulsifying cilostazol

Slopes from microbial curves of Burkholderia cepacia, Pseudomonas aeruginosa, Staphylococcus aureus, Candida albicans, and Aspergillus brasiliensis

Thickness, weight, tensile strength, elongation at break, young's modulus, and disintegration time of oroldispersible films

Activity, hardness, and roundness of pellets for oral lysozyme delivery

(Sovany et al., 2016)

Particle size, entrapment, permeation flux, and percentage release of aceclofenac loaded-nano structured lipid carriers

Size of microspheres, encapsulation efficiency of enoxaparin sodium, percentages released over $24 \mathrm{~h}$ in gastric, duodenal and colonic media

Particle size and particle size distribution of nanostructured lipid carriers containing salicylic acid for dermal use

Globule size, size distribution (PDI), percentage transmittance, and drug release of silymarin nanoemulsion

Antioxidant activity, and UVA and UVB radiation

(Garg et al., 2017)

(Hales et al., 2017)

(Kovács et al., 2017)

(Nagi et al., 2017)

(Peres et al., 2017)

Particle size, and entrapment efficiency of (Raina, Kaur, Jindal, efavirenz loaded solid lipid nanoparticles 2017)

In vitro drug release and viscosity at physiological $\mathrm{pH}$ of a microemulsion of lorazepam via

(Shah et al., 2017) intranasal route

Polydispersity index of miltefosine-loaded (Valenzuela-Oses polymeric micelles 
TABLE VIII - Examples of DoE applications for analytical methods development, experimental design adopted, independent variables (input factors - Xs), and dependent variables (output responses - Ys)

\begin{tabular}{|c|c|c|c|}
\hline $\begin{array}{l}\text { Experimental } \\
\text { design }\end{array}$ & Independent variables (Xs) & Dependent variables (Ys) & Reference \\
\hline $\begin{array}{l}\text { Fractionate factorial } \\
\text { design and central } \\
\text { composite design }\end{array}$ & $\begin{array}{l}\text { Culture media compositions (peptone, yeast } \\
\text { extract, beef extract, and dextrose), inoculum } \\
\text { proportion, triphenyltetrazolium concentration, } \\
\text { and neomycin concentration }\end{array}$ & Microbial growth of Escherichia coli & $\begin{array}{c}\text { (Francisco et al., } \\
\text { 2014) }\end{array}$ \\
\hline $\begin{array}{l}\text { 2-level factorial } \\
\text { design and central } \\
\text { composite design }\end{array}$ & $\begin{array}{l}\text { Microorganism, culture media, volume of seeded } \\
\text { culture medium, inoculum proportion, and } \\
\text { linezolid concentration }\end{array}$ & Inhibition zone sizes & $\begin{array}{l}\text { (Saviano, Francisco, } \\
\text { Lourenço, 2014) }\end{array}$ \\
\hline $\begin{array}{l}\text { Central composite } \\
\text { design }\end{array}$ & $\mathrm{pH}$, temperature, flow rate, and gradient slope & $\begin{array}{l}\text { Retention time, efficiency, and solvent } \\
\text { consumption in stability indicating UHPLC } \\
\text { method }\end{array}$ & $\begin{array}{c}\text { (Bousses et al., } \\
\text { 2015) }\end{array}$ \\
\hline $\begin{array}{l}\text { Box-Behnken } \\
\text { design }\end{array}$ & $\begin{array}{l}\text { Acetonitrile content in mobile phase, } \mathrm{pH} \text { of water } \\
\text { phase, and ammonium acetate concentration in } \\
\text { water phase }\end{array}$ & $\begin{array}{l}\text { Retention time of exo-iohexol, endo-iohexol, } \\
\text { and their related compound (A, B, and C) using } \\
\text { liquid chromatographic method }\end{array}$ & $\begin{array}{c}\text { (Jovanovic et al., } \\
\text { 2015) }\end{array}$ \\
\hline $\begin{array}{l}\text { Fractionate factorial } \\
\text { design and central } \\
\text { composite design }\end{array}$ & $\begin{array}{l}\text { Culture media compositions (peptone, } \\
\text { yeast extract, beef extract, dextrose, and } \\
\text { sodium choride), inoculum proportion, and } \\
\text { triphenyltetrazolium concentration }\end{array}$ & Microbial growth of Staphylococcus aureus & $\begin{array}{l}\text { (Saviano et al., } \\
\text { 2015) }\end{array}$ \\
\hline $\begin{array}{l}\text { 2-level factorial } \\
\text { design and central } \\
\text { composite design }\end{array}$ & $\begin{array}{l}\text { Culture media composition (yeast extract, } \\
\text { dextrose, beef extract, and peptone), } \\
\text { triphenyltetrazolium concentration, and } \\
\text { inoculum proportion }\end{array}$ & $\begin{array}{l}\text { Incubation time and microbial growth of } \\
\text { Staphylococcus aureus }\end{array}$ & $\begin{array}{c}\text { (Francisco et al., } \\
\text { 2016) }\end{array}$ \\
\hline $\begin{array}{l}\text { Central composite } \\
\text { design }\end{array}$ & $\begin{array}{l}\text { Triphenyltetrazolium concentration, incubation } \\
\text { time, nystatin concentration, and inoculum } \\
\text { proportion }\end{array}$ & $\begin{array}{l}\text { Absorbance of microbial growth of Candida } \\
\text { albicans }\end{array}$ & $\begin{array}{c}\text { (Jamil et al., } 2 \\
016)\end{array}$ \\
\hline $\begin{array}{l}\text { Box-Behnken } \\
\text { design }\end{array}$ & $\begin{array}{l}\text { Acetonitrile content in mobile phase, ammonium } \\
\text { acetate concentration in the aqueous phase, and } \\
\mathrm{pH} \text { of aqueous phase }\end{array}$ & $\begin{array}{l}\text { Retention factor of impurity and selectivity } \\
\text { of critical peal pair in bilastine and its } \\
\text { degradation impurities determination by liquid } \\
\text { chromatographic method }\end{array}$ & $\begin{array}{l}\text { (Terzic et al., } \\
\text { 2016) }\end{array}$ \\
\hline $\begin{array}{l}\text { Placket-Burman } \\
\text { design }\end{array}$ & $\begin{array}{l}\text { Temperature, } \mathrm{pH} \text {, buffer concentration, and } \\
\text { L-asparaginase concentration }\end{array}$ & $\begin{array}{l}\text { Absorvance at } 450 \mathrm{~nm} \text {, usedfor L-asparaginase } \\
\text { activity method }\end{array}$ & $\begin{array}{c}\text { (Yao et al., } \\
2016)\end{array}$ \\
\hline $\begin{array}{l}\text { Fractionate factorial } \\
\text { design }\end{array}$ & $\begin{array}{l}\text { Time of dissolution, volume of dissolution } \\
\text { media, pH of dissolution media, and rotation } \\
\text { speed }\end{array}$ & Amount of acetaminophen dissolved during & $\begin{array}{c}\text { (Romero, Lourenço, } \\
\text { 2017) }\end{array}$ \\
\hline
\end{tabular}

as recent examples of the utilization of DoE in the development and optimization of analytical methods.

DoE tools help to identify and explain how critical analytical parameters (CAPs) (independent variables) affects the analytical method performance characteristics (AMPC) (dependent variables) and, therefore, the analytical target profile (ATP). MODR may be defined based on DoE results. Working within MODR would not be considered as change, consequently it does not require method revalidation. Recently, FDA has approved new drug application based on analytical QbD. Implementation of $\mathrm{AQbD}$ provides robust analytical methods, which plays significant role in drug product development.In 2013, FDA and EMA initiated a joint research program 
concerning the $\mathrm{AQbD}$ concept. The objective is to define protocols for method transfer, methodology for validation of MODR, and define review criteria for evaluation of QbD based analytical methods. Also, USP Forum has published stimuli articles concerning to application of AQbD concepts.

The challenges for $\mathrm{QbD}$ and $\mathrm{AQbD}$ implementation include the harmonization of terminologies and concepts, training and education of human resources for industries and regulatory agencies, and the need of guidelines regarding documentation of knowledge generate during pharmaceutical and/or method development.

\section{ACKNOWLEDGEMENTS}

This work was supported by FAPESP - Fundação de Amparo à Pesquisa do Estado de São Paulo (São Paulo, Brazil) and CNPq - Conselho Nacional de Desenvolvimento Científico e Tecnológico (Brasília, Brazil).

\section{REFERENCES}

Badawi MA, El-Khordagui LK. A quality by design approach to optimization of emulsions for electrospinning using factorial and D-optimal designs. Eur J Pharm Sci. 2014;58:44-54.

Bezerra MA, Santelli RE, Oliveira EP, Villar LS, Escaleira LA. Response surface methodology (RSM) as a tool for optimization in analytical chemistry. Talanta. 2008;76(5):965-977.

Bhutani H, Kurmi M, Singh S, Beg S, Singh B. Quality by design $(\mathrm{QbD})$ in analytical sciences: an overview. Pharma Times. 2014;46(8):71-75.

Bousses C, Ferey L, Vedrines E, Gaudin K. Using an innovative combination of quality-by-design and green analytical chemistry approaches for the development of a stability indicating UHPLC method in pharmaceutical products. J Pharm Biomed Anal. 2015;115:114-112.

Candioti LV, De Zan MM, Cámara MS, Goichoechea HC. Experimental design and multiple response optimization. Using the desirability function in analytical methods development. Talanta. 2014;124:123-138.

Francisco FL, Saviano AM, Pinto TJA, Lourenço FR. Design space of a rapid colorimetric microplate bioassay for bacitracion using response surface methodology (RSM). Curr Anal Chem. 2016;12(6):620-627.
Francisco FL, Saviano AM, Pinto TJA, Lourenço FR. Development, optimization and validation of a rapid colorimetric microplate bioassay for neomycin sulfate in pharmaceutical drug products. J Microbiol Methods. 2014;103:104-111.

Garg NK, Sharma G, Singh B, Nirbhavane P, Tyagi RK, Shukla $\mathrm{R}$, Katare OP. Quality by design (QbD)-enabled development of aceclofenac loaded-nano structured lipid carriers (NLCs): an improved dermatokinetic profile for inflammatory disorder(s). Int J Pharm. 2017;517(1-2):413-431.

Hales D, Vlase L, Porav SA, Bodoki A, Barbu-Tudoran L, Achim M, Tomula I. A quality by design (QbD) study on enoxaparin sodium loaded polymeric microspheres for colonspecific delivery. Eur J Pharm Sci. 2017;100:249-261.

Jamil CRP, Lourenço FR, Ghisleni DDM, Pinto TJA. Development and validation of a microplate bioassay for nystatin using analytical quality by design $(\mathrm{QbD})$ approach. Lat Am J Pharm. 2016;35(8):1871-1876.

Jovanovic M, Rakic T, Tumpa A, Stojanovic BJ. Quality by design approach in the development of htdrophilic interaction liquid chromatographic method for the analysis of iohexol and its impurities. J Pharm Biomed Anal. 2015;110:42-48.

Kovács A, Berkó S, Csányi E, Csóka I. Development of nanostructured lipid carries containing salicylic acid for dermal use based on the quality by design method. Eur J Pharm Sci. 2017;99:246-257.

Krishna MV, Dash RN, Reddy BJ, Venugopal P, Sandeep P, Madhavi G. Quality by design (QbD) approach to develop HPLC method for eberconazole nitrate: application to hydrolytic, thermal, oxidative and photolytic degradation kinetics. J Saudi Chem Soc. 2016;20(Suppl 1):S313-S322.

Lourenço FR, Francisco FL, Ferreira MRS, Pinto TJA, BouChacra NA. Design space approach for preservative system optimization of an anti-aging eye fluid emulsion. J Pharm Pharm Sci. 2015;18(2):551-561.

Lourenço V, Lochmann D, Reich G, Menezes JC, Herdling T, Schewitz J. A quality by design study applied to an industrial pharmaceutical fluid bed granulation. Eur J Pharm Bio. 2012;81(2):438-447.

Muftaba A, Ali M, Kohli K. Formulation of extended release cefpodoxime proxetil chitosan-alginate beads using quality by design approach. Int J Bio Macromol. 2014;69:420-429. 
Nagi A, Iqbal B, Kumar S, Sharma S, Ali J, Baboota S. Quality by design based silymarin nanoemulsion for enhancement of oral bioavailability. J Drug Del Sci Technol. 2017;40:35-44.

Orlandini S, Paquini B, Caprini C, Del Bubba M, Dousa M, Pinzauti S, Furlanetto S. Enantioseparation and impurity determination of ambrisentan using cyclodextrin-modified micellar electrokinetic chromatography: visualizing the design space within quality by design framework. J Chromatogr A. 2016;1467:363-371.

Ostronoff CS, Lourenço FR. Measurement uncertainty of chromogenic LAL assays: reaction time and proportion of endotoxin and LAL reagent affect release of p-nitroaniline. $\mathrm{J}$ AOAC Int. 2015;98(1):51-55.

Peraman R, Bhadraya K, Reddy YP. Analytical quality by design: a tool for regulatory flexibility and robust analytics. Int J Anal Chem. 2015;2015:1-9.

Peres DDA, Ariede MB, Candido TM, Almeida TS, Lourenço FR, Consiglieri VO, Kaneko TM, Velasco MVR, Baby AR. Quality by design (QbD), process analytical technology (PAT), and design of experiment applied to the development of multifunctional sunscreens. Drug Develop Ind Pharm. 2017;43(2):246-256.

Politis SN, Colombo P, Colombo G, Rekkas DM. Design of experiments (DoE) in pharmaceutical development. Drug Develop Ind Pharm. 2017;43(6):889-901.

Pund S, Shete Y, Jagadale S. Multivariate analysis of physicochemical characteristics of lipid based nanoemulsifying cilostazol-Quality by design. Colloids Surf B Biointerfaces. 2014;115:29-36.

Raina H, Kaur S, Jindal AB. Development of efavirenz loaded solid lipid nanoparticles: risk assessment, qualityby design (QbD) based optimization and physicochemical characterization. J Drug Del Sci Technol. 2017;39:180-191.

Romero DC, Lourenço FR. Measurement uncertainty of dissolution test of acetaminophen immediate release tablets using Monte Carlo simulations. Braz J Pharm Sci. 2017;53(3):e00163.

Sangshetti JN, Deshpande M, Zaherr Z, Shinde DB, Arote R. Quality by design approach: regulatory need. Arab J Chem. 2017;10(Suppl 2):S3412-S3425.

Saviano AM, Francisco FL, Lourenço FR. Rational development and validation of a new microbiological assay for linezolid and its measurement uncertainty. Talanta. 2014;127:225-229.
Saviano AM, Francisco FL, Ostronoff CS, Lourenço FR. Development, optimization, and validation of a microplate bioassay for relative potency determination of linezolid using a design space concept, and its measurement uncertainty. J AOAC Int. 2015;98(5):1267-1275.

Shah V, Sharma M, Pandya R, Parikh RK, Bharatiya B, Shukla A, Tsai HC. Quality by design approach for an in situ gelling microemulsion of lorazepam via intranasal route. Mat Sci Enginn C. 2017;75:1231-1241.

Sovàny T, Csordás K, Kelemen A, Regdon Jr G, Pintye-Hódi K. Development of pellets for oral lysozyme delivery by using a quality by design approach. Chem Engin Res Design. 2016;106:92-100.

Terzic J, Popovic I, Stajic A, Tumpa A, Jancic-Stojanovic B. Application of analytical quality by design concept of bilastine and its degradation impurities determination by hydrophilic interaction liquid chromatographic method. J Pharm Biomed Anal. 2016;125:385-393.

Valenzuela-Oses JK, García MC, Feitosa VA, PachioniVasconcelos JA, Gomes-Filho SM, Lourenço FR, Cerize NNP, Bassères DS, Rangel-Yagui CO. Development and characterization of miltefosine-loaed polymeric micelles for cancer treatment. Mater Sci Eng C. 2017;81:327-333.

Verma S, Lan Y, Golhale R, Burgess DJ. Quality by design approach to understand the process of nanosuspension preparation. Int J Pharm. 2009;377(1-2):185-198.

Visser JC, Dohmen WMC, Hinrichs WLJ, Breitkreutz J, Frijlink HW, Woerdenbag HJ. Quality by design approach for optimizing the formulation and physical properties of extemporaneously prepared orodispersible films. Int J Pharm. 2015;485(1-2):70-76.

Yao H, Vancoillie J, D'hondt M, Wynendaele E, Bracke N, De Spiegeller B. An analytical quality by design $(\mathrm{aQbD})$ approach for a L-asparaginase activity method. J Pharm Biomed Anal. 2016;117:232-239.

Yu LX, Amidon G, Khan MA, Hoag SW, Polli J, Raju GK, Woodcock J. Understanding pharmaceutical quality by design. AAPS J. 2014;16(4):771-783.

Zhang L, Mao S. Application of quality by design in the current drug development. Asian J Pharm Sci. 2017;12(1):1-8. 